\section{CONTAGIOUSNESS OF CHOLERA. To the Editor of The LANCET.}

$\mathrm{SrR},-\mathrm{I}$ observe that many of my professional brethren are still sceptical as to the infectious nature of cholera.

If $I$ remember right, the following circumstance occurred in the last visitation of it. The children belonging to St. Pancras, who were at Drouett's establishment during that dreadful outbreak of cholera, were removed to their own workhouse. At that time there had been no cholera there, but many other children were immediately attacked, several of whom died.

Several children from this, St. Pancras Workhouse, were then taken to a detached house at Margate. Two adults residing in that honse were immediately attacked and died. There were no cases of cholera there previously nor subsequently, nor in Margate. Are these facts, or are they not? The norration of them at the time struck me forcibly; and, if true, are quite sufficient to convince. us that cholera is either infectious or contagious, perhaps both. Let us look the enemy in the face.

Colchester, Oct. 1853.

I am, Sir, your obedient servant,

JAMEs Morss Churchil.

\section{TRUTH v. THE BOARD OF HEALTH.} To the Editor of THE LANCET.

SrR,-In the last number of Tre LANCEr you replied to Mr. Gibson and other correspondents at Newcastle in flattering terms of the medical officer of the Board of Health at present in that town. Now, I do not wish to detract from the laurels or honours won by any man, more especially a medical gentleman, unless he first aitempts to do so himself; but falsehood, when attempted to be published to the world as facts, should be immediately destroyed in its swaddling clothes.

About a fortnight ago Dr. Gavin visited this town on his way to Whalton, and met here the members of the Local Board of Health and Board of Guardians, and on the 12th inst. a report from the General Board of Health appeared in the London morning papers respecting Morpeth, in which there was not a single line of truth, and which I contradicted in the Moning Chronicle of the 17th inst. Now, if every word of the report be construed in an opposite meaning to that which is intended, then it will be more applicable to this town. The question now is, Who sent the medical report?

Niorpeth, Oct. 18\%3.

I am, Sir, your obedient servant, M. J. O'CONNOR

\section{JUDICIOUS GENERAL BLOODLETTING.}

$$
\text { "Medio tutissimas ibis." }
$$

To the Elditor of THE LANCET.

SIR, - T have been so much gratified by reading the valuable, well-written, and highly interesting paper on "General Bloodletting, with Cases. By W. Cumming, Esq.," which appeared in THE LarCET of September lotl, ult., that I cannot refrain from adding my testimony to his on this important subject. Mr. Cumming is eviclently a careful observer, a judicious reasoner, and a cautious, and at the same time, (in every point of riew, a bold practitioner. He clearly perceives the error into which too many of the modern school have fallen, in totally rejecting what is by far the most important and valuable remedy in the hands of the physician, when wisely adopted in the treatment of acute sthenic disease, regulating quantity and frequency by the urgency of symptoms and state of the patient. True it is that much can be done by antimony, calomel, and opium, but these all act far better in highly acute cases after an early, well-adjusted bleeding, than where bleeding had been omitted. Moreover, I am well-persuaded that in modern times many a case of pneumonia, pleuritis, carditis, enteritis, and of inflammation in other vital organs, of apoplexy, \&c., has been lost by the omission of this highly essential remedy on the first appearance of the acute symptoms, and by trusting alone to large doses of antimony, \&c., the list of cases of permanent, lingering, distressing chronic disease has been extensively increased.

By my associations in the profession, and by the public announcements so frequently made, I am convinced that this remedy is decried to a most injurious extent, and, therefore, I gladly add the result of a very long experience to that of Mr. Cumming, an experience which has extended over a period of more than thirty years, in which, in a very large publie prac- tice, where acute cases in every variety of shade have been treated, not by scores only, but by hundreds in the year, the lancet has been most extensively, but judiciously, (especially as regards quantity of blood drawn, ) and most beneficially used, to the saving of many a case of inflammation in the heart, lungs, pleura, peritoneum, uterus, brain, \&c., which would have been allowed to die had none of our other usual remedies been adopted. The application of leeches is very inferior in effect and advantage to that produced by blood drawn from the arm, when adopted to the extent dictated by prudent experience. Large and repeated bleedings have no doubt killed many a patient, or have left many a sifferer in an anæmic and pitiable condition, but observing the "just medium" with this remedy, is a very different thing.

With regard to peritonitis, I may say, (with Dr. Armstrong of past times, " "I have never lost a case in my life" when called in within a reasonable time after the occurrence of the shivering fit, and that, because I have bled freely, and have given large doses of opium; and, in many a case of carditis, where there was scarcely any pulse, and where death seemed to be staring the patient in the face, and where many a practitioner would have said that stimulants were indicated, by the use of the lancet I have quickly restored the pulse, and banished all danger. I have no doubt that Mr. Cumming derived the first principles which led to this judicious treatment in acute disease from the same school from which I obtained my practice, -association with the London Hospital School, where in 1819,1820 , and 1821, bleeding was used to a very great extent, and very likely then sometimes to an injurions degree, but where also it was adopted to the saving of many an acute case. I therefore trust that the day is coming when the profession will review this great subject, and the now too long-continued and too fashionable custom of despising the lancet, will be superseded by one in which its great merits will be duly appreciated, and suffering humanity will again become blessed by its wise employment.

Within the last fifteen years I have had the assistance of clever young men, educated at different hospitals and schools, who at first could with difficulty be persuaded to adopt my practice, because they had been taught that it was next to murder, but who, after a very short time and observa. tion became convinced of its great advantage. In the year 1847, when the most extensive epidemic affecting the lungs and air passages prevailed that $I$ ever knew, two of my assistants witnessed my treatment by bleeding from six to sixteen ounces in adults, adopted on the accession of the acute symptoms, who, although sceptical at first, as to the propriety of adopting such a means, became perfect con. verts to the plan, from having witnessed its astounding success, and which they have carried with them into private practice, in which it has been attended by the same success.

Clapham-road, Oct. 1853.

I am, Sir, yours, \&c. J.T. Mitcheld, F.R.C.S.

\section{ROYAL MATERNITY CHARITY. To the Eclitor of THE LANCET.}

SrR,-I should not have intruded again upon your columns had it not been for one or two remarks in your leading article in reference to the above charity. I am glad to find you consider the amount paid to the physicians for the services now rendered to the charity "excessive" and so the committee think; and no doubt it will turn out eventually that the governors generally (with few exceptions) will come to the same conclusion. In your first paragraph you remark that there is some inconsistency in my recent statements and the notice of motion I gave in at the last general meeting; and I readily admit it; but I gave notice of such motion because I considered the course taken by the physicians not only im. politic, but unjust towards the true interests of the charity, looking at their, services rendered to the institution. If these gentlemen suppose the agitation of this question is at an end, they are very much mistaken; but there is a course open to them, which would most likely put an end to any further disputation and unpleasantness as respects the proper and reasonable amount of remuneration for the services they actually render to the charity, if they think proper to adopt such a course; and I am quite sure the committee entertain no hostile feeling in the matter, and that they would fairly meet a mode. rate and consistent proposition as to what should hereafter be the amount of remuneration to be paid to them. From your remarks upon the expense attending the midwives' cases, I was induced to make further inquiry as to the amount of fee paid to the midwife, and any other expense attending each 